\title{
A Systematic Review of Ethics Knowledge in Audiology
}

$$
\text { (1980 - 2010) }
$$

\section{Alida Maryna Naudé \& Juan Bornman}

Centre for Augmentative and Alternative Communication, University of Pretoria, South Africa

Corresponding author: Centre for AAC, University of Pretoria, Lynnwood Road, Pretoria, 0108, South Africa; alida@eaglecad.co.za; +27 83457 4262;

Word count: 4132

\begin{abstract}
Purpose: The purpose of this research was to apply multiple perspectives as part of a systematic review to analyse the literature regarding ethics in audiology. Audiologists are particularly vulnerable to the changing requirements of the discipline that compel them to straddle both professional obligations and business principles, creating a 'hybrid' professional.

Method: A two-phase mixed method approach was used to analyse publications. Publications were sorted into categories, namely approach to ethics, author, decade, role of the audiologist, component of morality, and common themes. The sample consisted of peer-reviewed papers cited in MEDLINE, CINAHL, ERIC, MasterFILE Premier, E-Journals, Africa-Wide Information and Academic Search Premier electronic database indexes, as well as non-peer-reviewed papers in the Seminars in Hearing professional journal.

Results: The publications were predominantly philosophical, focused on the rehabilitative role of the audiologist, and addressed the moral judgement component of moral behaviour.
\end{abstract}


Conclusions: Despite the fact that knowledge of ethics grew between 1980 and 2010, this retrospective analysis identified gaps in the current knowledge. Further research is needed to address the unique ethical problems commonly encountered in all eight roles of the audiologist; patient perspectives on ethics; ethical approaches; factors affecting moral judgement, sensitivity, motivation and courage; as well as the cultural dimensions of ethical practice in audiology. [201]

Key words: Audiology, ethics, morality, professionalism, systematic review

\section{INTRODUCTION}

Audiology in the $21^{\text {st }}$ century is characterised by technological advances such as genetic testing, cochlear implants, tele-audiology and hearing aid verification through the use of speech mapping. Progress in society as well as development in technology has placed healthcare professionals (including audiologists) under the ethical spotlight, bringing about an increased awareness of ethical dilemmas and the need for moral behaviour (Pera, 2011). This has led to increased discussions on professionalism which includes ethics, as well as its importance in shaping the public's perceptions of today's audiologists. Professionalism is defined as the acting out of the values and beliefs of individuals who serve those whose well-being is entrusted to them, by putting the client's interests first (Kirk, 2007). In order for audiologists to act in the best interest of their clients, it is important that psychological and social factors that influence the client's perceptions, expectations and behaviour be recognised. All clinical decisions regarding the client should therefore be aligned with the values and needs from various socioeconomic, ethnic, 
racial and religious backgrounds, and a range of gender and sexual identities (Kottler, 2010). Ethical dilemmas that form part of the daily practice of the audiologist range in complexity and include decisions about type of treatment, resource distribution, informed consent, confidentiality, whistle blowing and commercialisation. The struggle to find the right balance between these matters is especially relevant in an era when audiology as a professional discipline and audiology as a business practice are often integrated. A significant change in clinical direction came about following a legal decision in 1978 , which allowed audiologists to dispense hearing instruments to the public (Metz, 2000). It resulted in moving audiologists from being 'pure' professionals to being a hybrid between a professional and business practitioner (Resnick, 1993).

So what is ethics? This concept, also known as moral philosophy, dates back to Aristotle and ancient Greece. According to Williams (2009), "ethics is the study of morality - careful and systematic reflection on and analysis of moral decisions and behaviour, whether past, present or future". Morality in this sense refers to the actions taken on the basis of our values. Thus, ethics is concerned with the theory (knowing) of values, whereas morality is the practical application thereof (Williams, 2009). At a more fundamental level, ethics is a method by which values are categorised and pursued. It is about finding the balance between self-interest and social responsibility (Resnick, 1993).

The discipline of ethics provides one perspective for understanding the evolution of ethics in audiology. The field of ethics typically divides the study of ethics into philosophical ethics and social scientific ethics (Thiroux, 1995). These two ethical approaches differ in purpose and goal. 
Philosophical ethics on the one hand is concerned with what people ought to do and how they ought to conduct themselves, as well as the rational basis for these types of decisions. Its goal is to prescribe action, and to shed light on what 'ought' to happen. The philosophical approach to ethics embraces the deontological, utilitarian, virtue, and principles approaches (Beauchamp \& Childress, 1994). Different ethical theories can be applied to a variety of situations to inform our thinking and to support decision making. Deontological ethics is generally considered a normative stance that views the morality of an action in relation to fundamental principles, placing the focus of right and wrong on absolute adherence to rules, obligations, moral laws and duties. Deontological ethics is commonly contrasted to consequentialism and virtue ethics. Utilitarianism relates ethical responses to the outcome or consequence of an act. The central focus is the argument of 'maximising the greatest good for the greatest number'. Virtue ethics is a broad term for theories that focus on the role of character and virtue in moral philosophy. Most virtue ethics theories take their inspiration from Aristotle who declared that a virtuous person is someone who has ideal character traits. Lastly, principlism is a system of ethics based on four moral principles: autonomy, beneficence, non-maleficence and justice. This approach is commonly used in healthcare. Advocates for principlism argue that most moral decision makers in history have descriptively and prescriptively used these four moral principles, and that they are consistent with most intellectual, religious and cultural beliefs (Pera \& Van Tonder, 2011).

On the other hand, social scientific ethics (aka descriptive ethics) focuses on studying human ethical behaviour with empirical tools (Thiroux, 1995). Its goal is to explore what 'is' and consists of factual descriptions of moral conduct or beliefs (Thiroux, 1995). These descriptions often entail qualitative research studies into 
perception and attitude of professionals relating to moral rules and ethical concepts. The descriptive study of morality is merely concerned with stating what the actual beliefs of a person or group are. It does not pass moral judgements on conduct or beliefs; it merely describes what certain people believe to be right or wrong without judging these actions or beliefs (Pera \& Van Tonder, 2011).

To make an ethical decision requires both normative commitments and factual information. According to Nelson (2013), the traditional model of ethics that rigidly separates facts from values represents a limited model of ethical behaviour. There is a need for a multidimensional model of ethical behaviour to blend normative and empirical elements (Nelson, 2013), particularly in a 'hybrid' field such as audiology.

James Rest (1994) developed the Four Component Model of Moral Behaviour while working from a psychological perspective. His model contends that ethical behaviour involves at least four psychological components: ethical sensitivity (recognising and interpreting situations); moral judgement (making a decision about right or wrong and determining a course of action); moral motivation (putting ethical values before other values); and moral courage (persevering against adversity). He emphasises that the components are not steps, but psychological processes that may overlap and occur simultaneously.

Maintaining a high level of professional ethics is becoming more and more difficult because of competitive pressure. It is important that moral knowledge should keep pace with the increasing complexity and evolving professional autonomy of the audiology profession. Today's audiologists, regardless of where they are in their professional career, recognise that the changes in the scope of practice, especially with regard to hearing aid sales, present ethical challenges that create moral conflict and debate among themselves. Audiologists should make clinical decisions in terms 
of public benefit (best practice) and not self-interest. In this way, they distinguish themselves from businessmen by holding themselves to a higher standard than selfinterest (Resnick, 1993). In today's age of fast advancing technology and focus on putting the client first, ethics is not a luxury but central to the survival of the audiology profession. Therefore, it is legitimate to ask whether knowledge of ethics in audiology has kept pace with the increasing challenges in the field. One way of answering this question is to investigate the development of professional ethics in audiology by examining the published literature in this regard.

The primary purpose of this research was to use a multiple perspective, systematic review to describe and analyse the literature that examined ethics in audiology from 1980 to 2010 . The multiple perspectives used to analyse and describe the literature that examined ethics in audiology during that period included ethical approaches, topics and principles, components of moral behaviour and the role of the audiologist. The year in which the paper was published, as well as the type of journal was also described.

\section{METHOD}

\section{Sample}

The sample consisted of two different searches. Firstly, peer-reviewed journal papers cited in the MEDLINE, CINAHL, ERIC, MasterFILE Premier, E-Journals, Africa-Wide Information and Academic Search Premier electronic database indexes between 1980 and 2010 were searched. This resulted in a very small sample $(n=6)$. A second search was therefore necessitated. While searching the Seminars in Hearing professional non-peer-reviewed journal, an additional 21 relevant papers were found. This brought the total number of papers to 27 , which is regarded as a 
large sample, and hence no other non-peer-reviewed professional journals were consulted.

For the purposes of this study, the term 'audiology ethics' means explicit reflection on right or wrong behaviour in performing the professional role of the audiologist. There is some debate as to whether a distinction should be made between the terms 'ethics' and 'morality'. Those who distinguish ethics from morality argue that ethics involves systematic or conscious rational reflection, while morality refers to the complex personal and social rules and values that guide human conduct (Hinman, 1998; Purtilo, 1999; Thiroux, 1995). Because the topic of interest of this study was the body of knowledge that consciously reflects on right and wrong behaviour in the professional role of the audiologist, the term 'ethics' was most appropriate for this task.

Inclusion criteria were the following: (1) publication in indexed and peerreviewed journals, which was later expanded to also include professional journals between 1980 and 2010; (2) audiology ethics as an explicit major subject, topic, or key word; (3) primary target audience being audiologists; and (4) having been referenced or published in MEDLINE, CINAHL, ERIC, MasterFILE Premier, EJournals, Africa-Wide Information or Academic Search Premier.

Exclusion criteria were: (1) non-English language; (2) major topic not related to audiology ethics; (3) non-audiology target audience; (4) letters to the editor; (5) editorials; and (6) routine publication of professional codes of ethics, standards or position statements.

\section{Procedure}

During December 2012, a systematic literature search was conducted to identify peer-reviewed publications that addressed ethics in the profession of 
Audiology in the period 1980 to 2010 . Electronic databases were searched for the specified time period using the terms 'audiology' and ethics-related terms by using the truncation symbol * (e.g., 'ethic*', 'moral*', 'autonom', 'confidentiality', 'informed consent', 'moral reason*', 'moral judgement', 'justice', 'paternalism', 'care', 'duty’, 'responsibility', 'discrimination', 'attitud*', 'value*', 'best practice', 'problem solving', 'decision making'). The search used multiple search terms because of the lack of agreement on the terms 'ethics' and 'morality', the paucity of literature using the key word 'ethics', and the desire to include appropriate publications from different ethical approaches. Regardless of terminology, publications that did not consciously reflect on ethics were excluded from the papers that were categorised as described in the methodology. After search one, 56 papers were initially identified according to the titles. Based on the content of these papers, 50 were excluded from the sample as they either did not focus on audiology ethics per se, or were in the form of a letter to the editor of a journal. All the papers identified during the second search met the inclusion criteria. Together this resulted in a total of 27 papers found.

A two-phase mixed quantitative and qualitative research method was applied to analyse publications. Notes were made on each publication related to the descriptive categories and each was assigned a qualitative code. In the quantitative phase, descriptive techniques were used to identify the number of publications by author, country of publication, and journal of publication. The publications were then categorised according to decade (80s, 90s, 2000), ethical approach (being mostly philosophical, i.e. principle approach or being mostly social, i.e. case study approach), component of morality, the topic or ethical principle (e.g. autonomy, beneficence, confidentiality, conflict of interest, informed consent, justice, nonmaleficence, research integrity, record keeping, risk management and veracity) and 
primary role of the audiologist as described in the literature (e.g. prevention, identification, assessment, diagnosis, rehabilitation, counselling, advocacy/ consultation, as well as education/research/administration) (Stach, 2010).

Another way in which the data was sorted involved categorising each publication according to the main component of morality addressed, using Rest's Four Component Model. Because some overlap exists among moral sensitivity (MS), moral judgement (MJ), moral motivation (MM), and moral courage (MC), the determining factor in classification was the purpose of the paper.

Qualitative analysis generally followed the format of Miles and Huberman (1994) in assigning codes, making notes, sorting, and sifting to identify themes. During this phase of the research, descriptive results were clarified and themes, patterns, as well as similarities within the publications were identified. For example, a number of different a priori categories were used to sort the publications by issue or topic. These categories included philosophical principles (autonomy, justice, beneficence, veracity, confidentiality, and informed consent), setting, and focus of relationships. After determining issues for each paper, the data was sorted into the three decades involved and analysed to determine topical themes for each decade.

After the initial analysis, a second assessor independently analysed the papers. The percentage of inter-rater agreement was calculated by dividing the number of observations that agree by the total number of observations. Initially interrater agreement of $93 \%$ was found. The two raters discussed the data until $100 \%$ inter-rater agreement was reached.

Both raters shared the same professional background. They were registered with the Health Professions Council of South Africa (HPCSA) as audiologists and speech language pathologists. Regarding experience, the first rater had 13 years of 
clinical practice in the field of audiology and frequently presented seminars and workshops in the field of ethics. The second rater had 22 years of experience, first clinically and currently in academia.

Table 1

Results presented chronologically, highlighting the identified categories

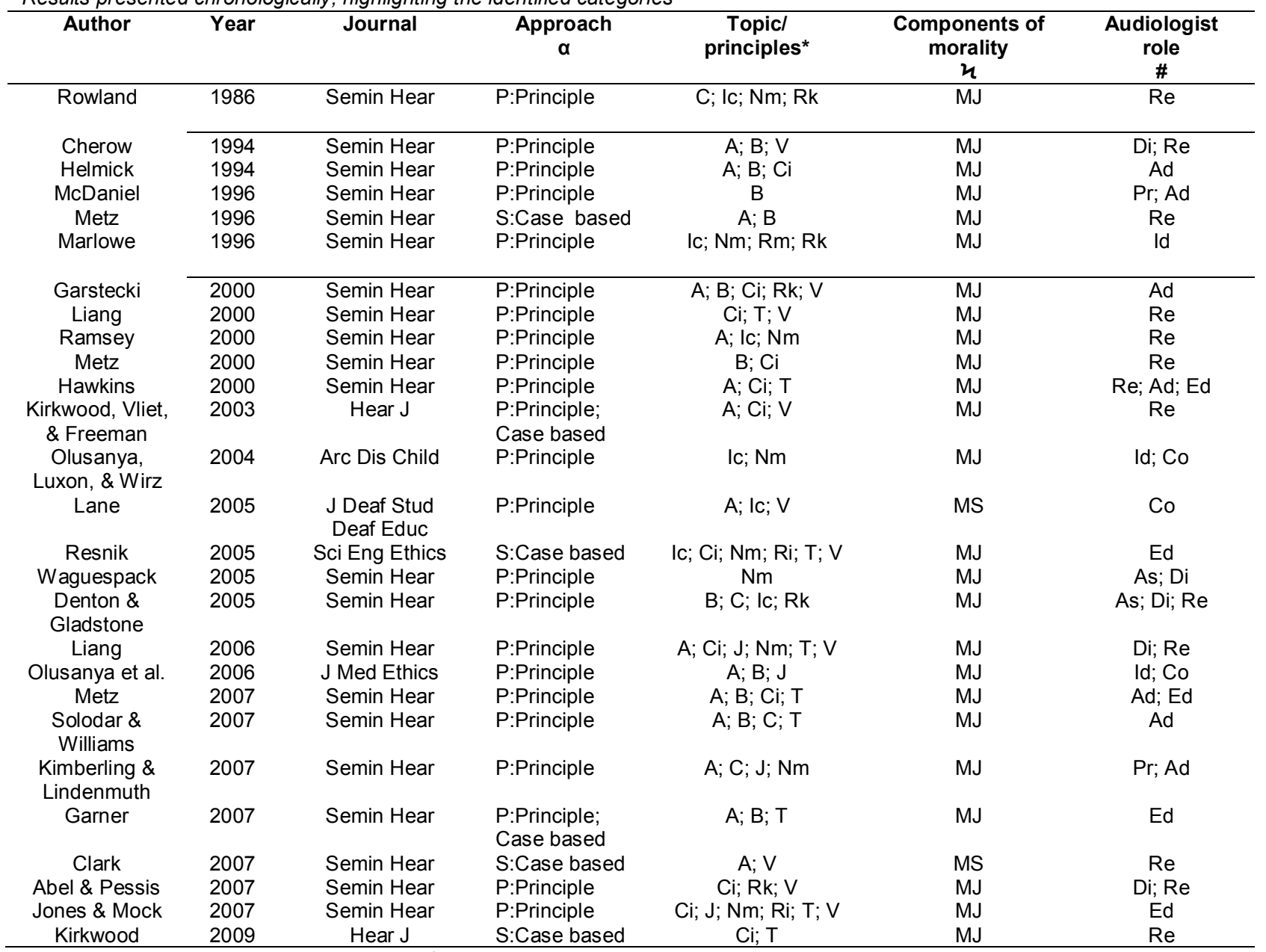

Note: The abbreviations used under the last four headings are described below.

$\alpha$ : $P=$ Philosophical $S=S o c i a l$

*: A=Autonomy $\quad B=$ Beneficence $\quad C=$ Confidentiality $\quad \mathrm{Ci}=$ Conflict of interest $\quad \mathrm{IC}=$ Informed consent $\mathrm{J}=\mathrm{J}$ ustice $\mathrm{Nm}=$ Non-maleficence

$\mathrm{Ri}=$ Research integrity $\mathrm{Rk}=$ Record keeping $\quad \mathrm{Rm}=$ Risk management $\quad \mathrm{T}=$ Trust $\quad \mathrm{V}=$ Veracity

и: MS=Moral sensitivity $\quad \mathrm{MJ}=$ Moral judgement $\mathrm{MM}=$ Moral motivation $\quad \mathrm{MC}=$ Moral courage

\#: Pr=Prevention Id=Identification As=Assessment Di=Diagnosis Re=Rehabilitation/management Co=Counselling

$\mathrm{Ad}=$ Advocacy/consultation $\quad \mathrm{Ed}=$ Education/research/administration

\section{RESULTS}

Twenty-seven papers published between 1980 and 2010 in five peerreviewed journals (Hearing Journal, Archives Dis Child, Journal of Deaf Studies and Deaf Education, Science and Engineering Ethics, Journal of Medical Ethics) and in one professional non-peer-reviewed journal (Seminars in Hearing) met the inclusion 
criteria. Table 1 contains a summary of the results. Papers are presented chronologically, starting with the oldest publications to the most recent, and include a reference to the author, the year of publication, journal name, the ethical approach followed, the topics and principles addressed, the specific components of morality according to Rest's Four Component Model, as well as the primary role of the audiologist.

The total number of authors involved in the 27 papers was 29 . There was a significant increase in the number of relevant publications and journals published in the course of the most recent decade (2000-2010). Of all the journals in this sample, the professional non-peer-reviewed journal, Seminars in Hearing, published the highest number of papers $(n=21 ; 78 \%)$. This may be interpreted to show that the ethical dilemma brought on by hearing aid dispensation is highly relevant to practising professionals, thus causing their profuse publication of articles in a professional journal. The results could also be indicative of a paucity of research in the field of ethics in audiology (hence the limited number of publications in peerreviewed indexed journals). It is interesting to note that although all of the six peerreviewed papers had a definite audiology focus, three were published in nonaudiology journals. One paper was published in an engineering ethics journal, one in a medical ethics journal and yet another in an educational journal. This emphasises the importance of not limiting one's initial search to discipline-specific journals.

\section{Approach}

Sorting publications into the two a priori categories of ethical approach (philosophical or social scientific) indicated that $85 \%$ of the papers $(n=23)$ were based on a philosophical approach, while only $15 \%(n=4)$ reflected a social scientific approach. The latter four papers appeared between 2002 and 2009, and their 
authors made use of a case study approach. All the authors in the philosophical category, however, adopted a principles approach.

\section{Issue or Topic}

The one paper written between 1980 and 1989 discussed the legal implications of a professional dispensing practice. In the decade between 1990 and 1999, the topical themes of the five papers focused on professional ethical issues in private practice. Themes for the most recent period (2000-2010) included responsible conduct of research, business ethics (conflict of interest), tele-audiology, genetics, malpractice, continued professional education, informed consent, as well as the ethical principles of autonomy, beneficence, non-maleficence, veracity and trust.

\section{Four Components of Morality}

Moral judgement was emphasised in the majority of publications (93\%), while only two publications $(7 \%)$ addressed moral sensitivity. The latter two papers were published in the most recent decade. None of the publications focused on moral motivation or on moral character.

\section{Role of the Audiologist}

Eleven of the papers (41\%) discussed the multiple roles of the audiologist and mentioned more than one of the possible eight roles of the audiologist as identified for the purpose of this paper. Altogether $48 \%(n=13)$ of the papers either explicitly or implicitly emphasised the rehabilitation/management role of the audiologist in terms of the dispensing of hearing aids (Table 1). The role that received the second highest amount of attention was advocacy $(n=7 ; 26 \%)$, followed by the audiologist's role in the process of diagnosis $(n=5 ; 19 \%)$, and his/her educational/research/administrative role $(n=5 ; 19 \%)$. Two roles, namely counselling and identification were mentioned in 
$11 \%(n=3)$ of the papers, while the remaining two roles - prevention and assessment - were each mentioned in $7 \%(n=2)$ of the papers.

\section{DISCUSSION AND CONCLUSION}

In this systematic review spanning 1980 to 2010 , literature on ethics in audiology was analysed. Over the three decades covered by the study, there was an increase in the number of papers, as well as the publication of social scientific studies. The increase in the number of publications is consistent with the technological growth and expanded scope of practice of the profession and reveals the growing extent of reflection within the profession on practice and the implications of audiologists' actions.

Our results suggest that knowledge of ethics in audiology used to be predominantly philosophical in approach until the social scientific approach started to emerge in the $21^{\text {st }}$ century. This focus of papers can be explained by reflecting on the ethical focus of the professional Code of Ethics for audiologists, as well as the reliance of the philosophical approach on principlism or the 'four principles approach' (Pellegrino, 1999). The principles perspective uses the philosophical concepts of common morality - autonomy, beneficence, non-maleficence and justice - as the basis for ethical decision making. The professional Code of Ethics incorporates these fundamental principles to promote the preservation of the highest standards of integrity and responsible discharge of obligations by all audiologists.

The focus on philosophical ethical principles is, however, not adequate to explain and understand the complexity of psychosocial, economic, sociological, legal, cultural, religious, and organisational factors involved in moral dilemmas. According to Pellegrino (1999), attention to each of the three threads (human values, philosophical ethics, and social and behavioural sciences) is critical in the emerging 
interdisciplinary synthesis of global bioethics, because ethical challenges are inherently multidimensional. It is, however, promising to note that the focus seems to be shifting increasingly towards a social scientific case study approach.

Although it is important for audiologists to have access to papers that can guide them in clinical and ethical decision making, it is also essential to determine what is currently happening in professional clinical practice. Social science is characterised by a greater focus on accountability and assessing how professionals are adapting to changing social environments. Professional ethics focuses not only on establishing commitment and accountability to other healthcare professionals, but also fosters a true partnership with patients as persons. This takes place against the social backdrop of a growing emphasis on patients' rights and teamwork in healthcare.

Patients are playing a more active role in the management of their own health and worldwide there has been a focus on patient empowerment in the form of knowing their rights. This is in line with the paradigm shift during the past decade away from the medical model of service delivery to a biopsychosocial model of healthcare. The focus is on patient autonomy as well as the importance of professionals to recognise the effect of both psychological and social factors on a patient's perceptions and actions (Metz, 2000). As a result of this shifting focus, the professional language changed from working with 'patients' who require medical treatment or care, to working with 'clients' who use professional advice and services for their own benefit in order to make decisions about their own health management. The term 'client' is, however, also used in relation to the business model, which is focused on generating revenue to make profit. Therefore, the term 'client' might 
erroneously accentuate the business side of the audiology field and could possibly contribute to the way professionals view those whom they serve.

Audiologists as healthcare professionals are entrusted by society to provide expert professional services and to commit themselves to the well-being of their clients. This has placed healthcare professionals, including audiologists, under an ethical spotlight, bringing about an increased awareness of ethical dilemmas and the need for moral behaviour. In the busy day-to-day activities associated with professional life, reflection on daily conduct is needed to obtain greater clarity regarding ethical decisions, professional duties and potential pitfalls in clinical practice. Social science research, which together with critical thinking will facilitate ethical decision making, can facilitate increased awareness of ethical issues experienced in the field (Purtilo, 1999).

The papers selected for this study mainly address the moral judgement component of moral behaviour. This was to be expected since moral judgement is considered to be the easiest component of morality to be measured and it usually constitutes the primary focus of any ethical analysis in general (Rest, 1994). The audiology profession seeks to maintain high standards of conduct and moral judgement through the moral principles and rules stated in its Code of Ethics to foster personal integrity in professional conduct (Helmick, 1994). This highlights the profession's emphasis on moral judgement. Concentrating on aspects related to current clinical practice as addressed by social research approaches could possibly widen the focus to other components of morality as identified by Rest's Four Component Model.

The main focus of all the evaluated papers in terms of the role of the audiologist was on rehabilitation - more specifically on the fitting of hearing aids. 
This finding is not surprising. A sharp increase occurred in papers published during the last decade that predominantly deal with the dispensing of hearing aids. The latter is the single largest contributor to the ethical dilemmas that face audiologists practising in the $21^{\text {st }}$ century. An ethical concern of this magnitude could easily mask the existence of smaller, yet important, ethical issues relevant to the other professional roles of the audiologist. This finding points to the need for further research to cover the broad and diverse role of the audiologist and address common issues that face the profession on a daily basis.

Although the focus of papers changed over the three decades, three recurrent themes were noted across the entire 30 years: (1) professional ethical issues in private practice, (2) business ethics, and (3) malpractice. Not one of the publications in the sample addressed the perspective of the client on ethical issues in audiology. Since the focus of the audiologist is to provide good client-centred care, the ethical issues have significance only if clients are indeed benefited by our concerns with such issues. It is hoped that future research will therefore include the client's view.

This paper began by posing the question: Has ethical knowledge in audiology kept pace with the challenges of increasing professional autonomy? Although the body of knowledge of ethics in audiology grew steadily from 1980 to 2010, our systematic review identified gaps in the current knowledge. Future research should address the unique ethical problems commonly encountered in all eight roles of the audiologist. Adequately addressing gaps in knowledge of ethics will require both philosophical and social scientific research using a multidimensional framework to guide inquiry. Four different sets of questions could contribute to research in audiology ethics. 
Firstly, questions could focus on moral sensitivity. What are the ethical issues that audiologists routinely encounter? What ethical issues are frequently overlooked by audiologists? How does organisational context or setting influence the recognition or interpretation of ethical issues?

Secondly, research questions could focus on moral judgement. What type of moral reasoning do audiologists need and what do they use? Does gender, religion, or culture influence moral judgements? What should an audiologist do in response to frequently encountered ethical dilemmas? What level of informed consent is necessary prior to assessment and specific interventions?

Thirdly, moral motivation questions could include: Do audiologists' view of their professional role cause them to advocate for their patients? What organisational, contextual, or policy factors act as barriers or resources to ethical behaviour?

Fourthly, questions on moral courage might include: Who are moral role models in audiology? What are the qualities of moral role models? What factors influence some audiologists to overcome obstacles to moral behaviour? What are the important implementation skills in adverse situations?

The results of this research reveal the need for further investigation into the area of audiology ethics. Given the close relationship between clinical and ethical decision making, research on the ethical role of the audiologist is crucial to the field. Such research would ensure that knowledge of ethics in audiology continues to grow by building on previous knowledge and simultaneously responding to the needs of the profession. Ethics is integrated in healthcare and key to releasing thoughtful therapists who act morally, in a purposive fashion, as a result of problem solving through ethical reflection. 


\section{REFERENCES}

Abel, D., \& Pessis, P. (2007). Reimbursement, Practice Management Issues, and Ethics. Seminars in Hearing, 28(3), 171-179. doi:10.1055/s-2007-982898.

Beauchamp, T. L., \& Childress, J. F. (1994). Principles of Biomedical Ethics (4th ed.). New York: Oxford University Press.

Cherow, E. (1994). Professional Autonomy: Then is Now. Seminars in Hearing, 15(3), 178189.

Clark, J. G. (2007). Patient-centered practice: aligning professional ethics with patient goals. Seminars in Hearing, 28(3), 163-170.

Denton, D. R., \& Gladstone, V. S. (2005). Ethical and Legal Issues Related to Telepractice. Seminars in Hearing, 26(1), 43-52.

Garner, G. D. (2007). The LASER Approach : Ethical Considerations in Continuing Education. Seminars in Hearing, 28(1), 65-71. doi:10.1055/s-2006-958913.

Garstecki, D. C. (2000). Moral, Ethics, Law, and Clinical Audiologists. Seminars in Hearing, 21(1), 21-32.

Hawkins, D. B. (2000). Conflicts of interests and the audiologist. Seminars in Hearing, 21(1), 33-40.

Helmick, J. W. (1994). Ethics and the Profession of Audiology. Seminars in Hearing, 15(3), 190-197.

Hinman, L. M. (1998). Ethics: A Pluralistic Approach (2nd ed.). Philadelphia: Harcourt Brace College.

Jones, S. M., \& Mock, B. E. (2007). Responsible Conduct of Research in Audiology. Seminars in Hearing, 28(3), 206-215. doi:10.1055/s-2007-982902.

Kimberling, W. J., \& Lindenmuth, A. F. (2007). Genetics, Hereditary Hearing Loss, and Ethics. Seminars in Hearing, 28(3), 216-225. doi:10.1055/s-2007-982903.

Kirk, L. M. (2007). Professionalism in medicine: definitions and considerations for teaching. Proc (Bayl Univ Med Cent), 20(1), 13-16.

Kirkwood, B. D. H., Vliet, D. Van, \& Freeman, B. (2003). Survey of dispensers finds little consensus on what is ethical practice. The Hearing Journal, 56(3), 19-26.

Kirkwood, D. H. (2009). Survey on ethics finds dispensers divided on how to practice on the side of the angels. The Hearing Journal, 62(3), 19-26.

Kottler, J. (2010). On Being a Therapist (4th ed.). San Francisco: Jossey-Bass.

Lane, H. (2005). Ethnicity, ethics, and the deaf-world. Journal of Deaf Studies and Deaf Education, 10(3), 291-310. doi:10.1093/deafed/eni030 
Liang, B. A. (2000). Fraud and Abuse in Audiology: The Law of Conflict of Interest. Seminars in Hearing, 21(1), 41-61.

Liang, B. A. (2006). Law and Audiology Practice : Understanding Malpractice and Conflict of Interest Rules. Seminars in Hearing, 27(1), 48-56.

Marlowe, J. A. (1996). Legal and Risk Management Issues in Newborn Hearing Screening. Seminars in Hearing, 17(2), 153-164.

McDaniel, M. (1996). Professional Issues in Hearing Conservation. Seminars in Hearing, 17(3), 253-259.

Metz, M. (2007). Business Ethics. Seminars in Hearing, 28(3), 186-197. doi:10.1055/s-2007982900

Metz, M. J. (1996). Service Delivery Issues in Private Practice. Seminars in Hearing, 17(3), 283-294.

Metz, M. J. (2000). Some ethical issues related to hearing instrument dispensing. Seminars in Hearing, 21(1), 63-74.

Miles, M. B., \& Huberman, A. M. (1994). Qualitative Data Analysis: An Expanded Sourcebook (2nd ed.). Thousand Oaks: California: Sage.

Nelson, J. L. (2013). Moral Teachings from Unexpected Quarters: Lessons for Bioethics from the Social Sciences and Managed Care. The Hastings Center, 30(1), 12-17.

Olusanya, B. O., Luxon, L. M., \& Wirz, S. L. (2004). Infant hearing screening: route to informed choice. Archives of disease in childhood, 89(11), 1039-40. doi:10.1136/adc.2004.051086

Olusanya, B. O., Luxon, L. M., \& Wirz, S. L. (2006). Ethical issues in screening for hearing impairment in newborns in developing countries. Journal of Medical Ethics, 32(10), 588-91. doi:10.1136/jme.2005.014720

Pellegrino, E. D. (1999). The Origins and Evolution of Bioethics: Some Personal Reflections. Kennedy Institute of Ethics Journal, 9(1), 73-88. doi:10.1353/ken.1999.0006

Pera, S. (2011). The moral and ethical foundation of nursing. In A. Oosthuizen \& D. Van der Wal (Eds.), Ethics in healthcare (3rd ed.). Lansdowne: Juta.

Pera, S., \& Van Tonder, S. (2011). Ethics in Healthcare. (G. Younge, Ed.) (3rd ed.). Lansdowne: Juta.

Purtilo, R. B. (1999). Ethical Dimensions in the Health Professions (3rd ed.). Philadelphia, Pa: Saunders Co.

Ramsey, C. L. (2000). Ethics and Culture in the Deaf Community Response to Cochlear Implants. Seminars in Hearing, 21(1), 75-86.

Resnick, D. M. (1993). Professional Ethics for Audiologists and Speech-Language Pathologists. San Diego: Singular Publishing Group, Inc. 
Resnik, D. B. (2005). Using Electronic Discussion Boards to Teach Responsible Conduct of Research. Science and Engineering Ethics, 11(4), 617-630.

Rest, J. R. (1994). Background: Theory and research. In J. R. Rest \& D. Narvaez (Eds.), Moral development in the professions: Psychology and applied ethics. (pp. 1-25). Hillsdale NJ: Lawrence Erlbaum.

Rowland, R. (1986). Legal Implications of a Professional Dispensing Practice. Seminars in Hearing, 7(2), 193-197.

Solodar, H., \& Williams, K. (2007). Ethics and Marketing. Seminars in Hearing, 28(3), 198205. doi:10.1055/s-2007-982901.

Stach, B. A. (2010). Clinical Audiology: An Introduction. Stamford, CT: Delmar Cengage Learning.

Thiroux, J. P. (1995). Ethics: Theory and Practice (5th ed., pp. 6-7). Englewood Cliffs, NJ: Prentice-Hall.

Waguespack, G. M. (2005). The Regulation of Telepractice in the Profession of Audiology. Seminars in Hearing, 26(1), 53-55.

Williams, J. R. (2009). World Medical Association Medical Ethics Manual (2nd ed.). France: The World Medical Association, Inc. 